\title{
Simulated output of Continuous Interleaved Sampling and Frequency Amplitude Modulation Encoding techniques used in Cochlear Implant
}

\author{
Deepti Gupta, Pratistha Mathur, Peeyush Tewari
}

\begin{abstract}
Cochlear Implant (CI) is an excellent electronic device to overcome congenital or profound hearing loss in humans. It provides an alternative to the natural hearing for the hearing-impaired humans in the form of artificial electrical hearing. Several coding techniques such as Continuous interleaved sampling (CIS) and Frequency amplitude modulation encoding (FAME) is used in CI for the conversion of analog signal to the digital one. This study is intended to assess the performance level of these two techniques in music, vowels, words perception with different channels to assess the quality of hearing in hearing impaired person.
\end{abstract}

Keywords: Cochlear Implant (CI), frequency modulation (FM), amplitude modulation (AM), speech perception, temporal envelope, continuous interleaved sampling (CIS), frequency amplitude modulation encoding (FAME).

\section{INTRODUCTION}

Advent of new technologies has brought about tremendous improvements in the life of a hearing impaired person in last few years by making appropriate changes in signals and putting them to useful applications. For good speech perception, envelope extraction of the speech signal is a critical step and requires Fourier approach. In Fourier analysis, speech signal is decomposed in either of two forms i.e. amplitude and frequency. Amplitude modulation technique is the preferred one which gives satisfactory results in the noise free environment [1]. However, in reallife applications where noise is an integral part of any speech, both frequency and amplitude modulations fail to provide satisfactory envelope extraction individually. In such scenario combination of frequency and amplitude modulations has been the recipe of the optimum results as far as the envelope extraction is concerned. From the acoustic cues, parameters such as vocal cord vibration status can be analyzed to demonstrate whether speech is voiced or unvoiced. The manner of articulation gives temporal cues defining speech and silent durations as well as the place of articulation as they produce spectral cues as frequency formants.

Manuscript published on November 30, 2019

* Correspondence Author

Deepti Gupta*, Computer Science, Banasthali Vidyapith University, Jaipur, India. Email: 29.deepti@gmail.com

Pratistha Mathur, Information Technology, Manipal University Jaipur, Jaipur, India. Email: pratistha.mathur@jaipur.manipal.edu

Peeyush Tewari, Applied Science, Birla Institute of Technology, Noida, India. Email: peeyushtewari@gmail.com

(C) The Authors. Published by Blue Eyes Intelligence Engineering and Sciences Publication (BEIESP). This is an open access article under the CC-BY-NC-ND license http://creativecommons.org/licenses/by-nc-nd/4.0/
Hence, it is possible to identify not only the speech but also the speaker and his emotions from acoustic cues. Amplitude modulation used along with frequency modulation gives satisfactory results with respect to speaker's identification, sound localization, tonal language identification and music identification.

FAME 'Frequency Amplitude Modulation Encoding' on the other hand, can convert fast varying temporal component into slowly varying amplitude as well as frequency modulation signals. CI provides temporal cues instead of natural one to the user and it makes a big difference in the speech. Therefore, the use of FAME is a better option compared to CIS 'Continuous Interleaved Sampling' [2].

\section{BACKGROUND}

Normal hearing is generally impaired due to some deficiency in the cochlea such as hair cell damage, conversion of cochlea fluid into bone because of some infection and damage to some auditory nerves. There can be many other reasons as well, such as congenital hearing defects, heredity, old age, continuous exposure to high $\mathrm{dB}$ sound etc. In such cases the CI 'Cochlear Implant' is the only solution as it facilitates the listening activity. Generally two encoding schemes CIS and FAME are used in cochlear implant to covert analog signals to digital one. Following two subsections give the overview of these two techniques.

\section{CONTINUOUS INTERLEAVED SAMPLING}

In CIS during amplitude modulation, energy of signals gets conserved and enables the speech signals to pass from source to destination without any alterations to the intensities. AM codes temporary envelope of the speech signal, compression also needs to be done because complete signal strength cannot be sent directly to the electrodes due to limited numbers of frequencies available for the user because of different kinds of hearing deficiencies [6]. In the end, CIS converts the signal into biphasic pulses and send it to the electrodes in non-simultaneous fashion. This process can be seen by Fig 1 [3].

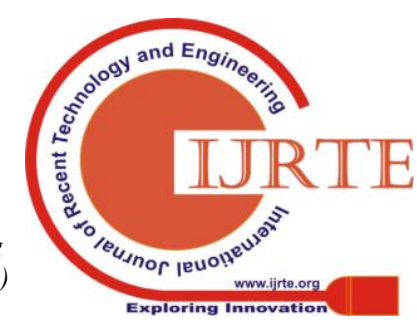



techniques used in Cochlear Implant

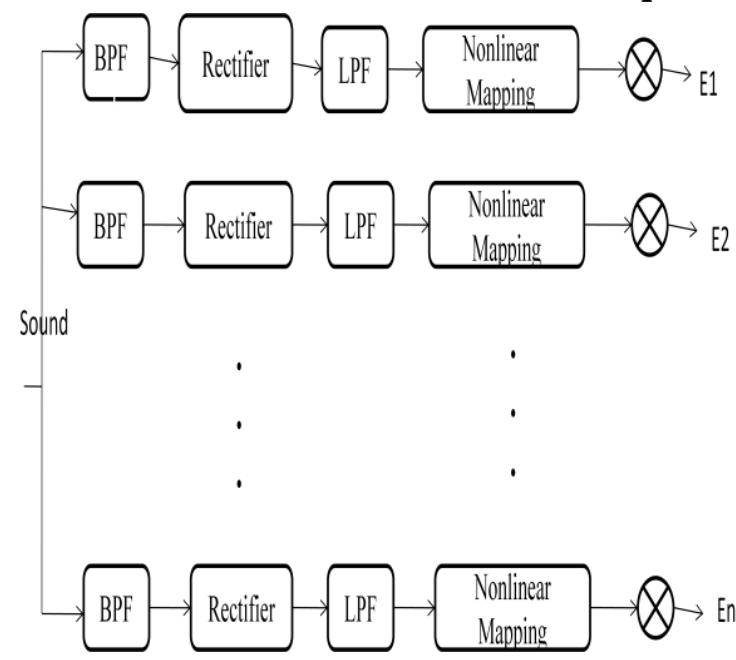

Fig.1 Block Diagram of CIS

\section{FREQUENCY AMPLITUDE MODULATION ENCODING}

Every speaker has a unique tone which helps a person with normal hearing to identify the speaker through his/her voice. In FAME, amplitude and frequency modulations work individually because of which signal energy is conserved leading to many benefits such as identification of the speaker along with his/her formants and tone. These characteristics of frequency modulation give more clarity in sound to the user. FM codes temporal fine structure from the speech signal. The unique feature of FAME is that the amplitude and frequency modulation combine to get the output in the form of signals. These signals reach the electrodes in the form of biphasic pulses [6].

The FAME separately extracts the slowly varying amplitude and frequency modulations within each frequency band (Fig 2 Block diagram). The FM codes the temporal fine structure of the speech wave form, whereas the AM separately codes the temporal envelope. The instantaneous amplitude of the FM carrier frequency is determined from the temporal envelope in the corresponding band. The signal is first divided into $n$ narrow bands, followed by the transmittance to the separate AM and FM extraction pathways. The AM pathway involves full-wave rectification followed by lowpass filtering at $500 \mathrm{~Hz}$ to obtain the slowly varying envelope. The FM pathway involves removal of each narrow band's center frequency followed by low-pass filtering of the FM bandwidth with a cutoff of $500 \mathrm{~Hz}$ (Fig 1 and 2 will be print at same place) $[4,5]$.

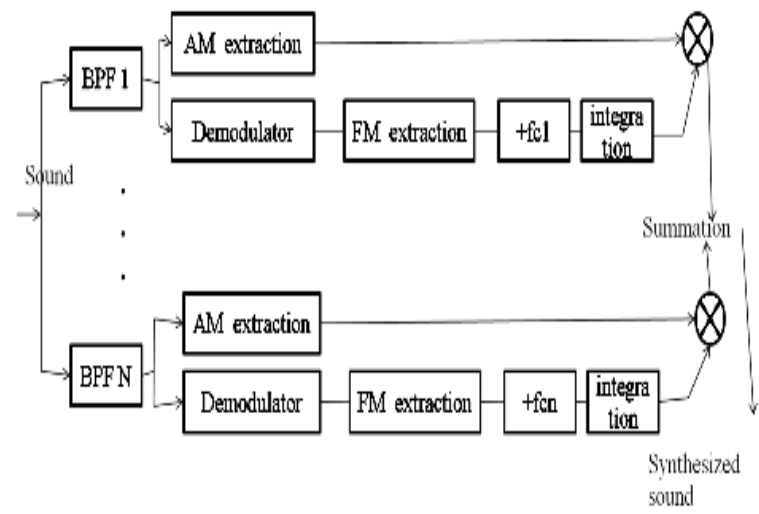

Fig.2 Block Diagram of FAME
Here we are doing a full wave rectification which involves the conversion of negative phase into positive one based on full wave rectifier principle. CI users due to loss of hearing capability either don't have low frequency active areas or very little active areas of low frequencies. Hence, full wave rectification doesn't lose any information of significance for the CI users. However, all CI devices leave lower frequencies in their processor programming [7].

In FAME (Fig 2) two processes are done simultaneously, amplitude and frequency modulations. As a research interface, frequency modulation is additional to the CIS. In the first step of the process, signal is demodulated and followed by frequency modulation, calculation of central frequency and integration of the signal. Finally, the amplitude and frequency modulated signals are combined to give the optimum output.

Success of CI depends on number of factors. The CI users whose language is developed before hearing loss can perform approximately like normal users. The user's, who are using CI from their childhood, respond to the system approximately similar to the normal user, which is unlike the scenario of users implanted by CI at the later stage of life. Early implantation helps in proper language development and success of CI depends upon many factors such as efficiency of members of the CI team like surgeon, audiologist, speech language pathologist, and educational consultant. Another important factor is user's willingness to learn the usage of the cochlear implant device [8].

\section{EXPERIMENTAL DESIGN}

All sentences and words recordings have been done by a male speaker with an Indian English accent in an anechoic chamber. For CI subjects training is required to make them familiar with the apparatus and protocol of the experiments. Few new words need to be exposed to CI subjects. All CI subjects are not old enough to understand all the words so few new words need to be exposed to them. Familiarization of all the words by all the subjects is necessary for the appropriate conclusion of the experiment.

\section{A. Methodology: In the methodology the steps are}

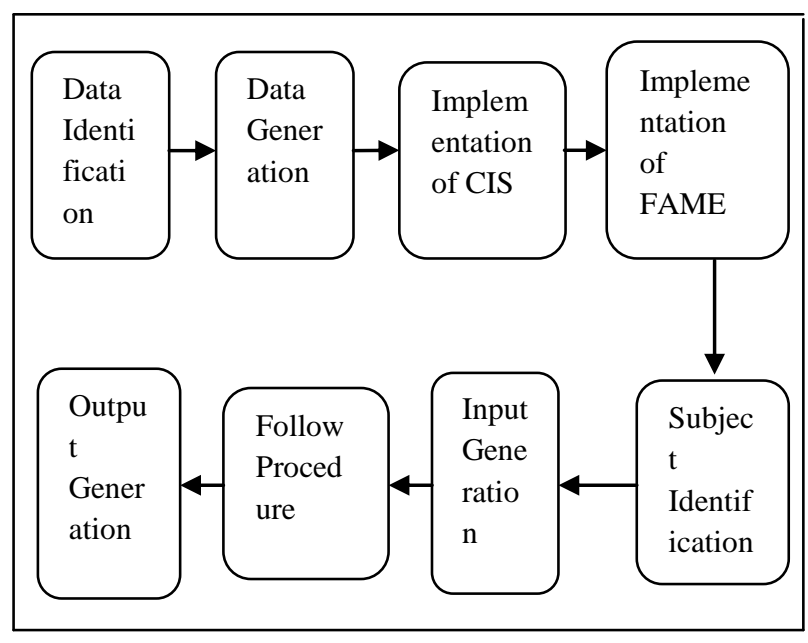

Fig.3 Block Diagram of Methodology

defined which are followed by us to complete the experiments. The steps are clearly shown in the Fig 3.

Published By:

Blue Eyes Intelligence Engineering and Sciences Publication (BEIESP)

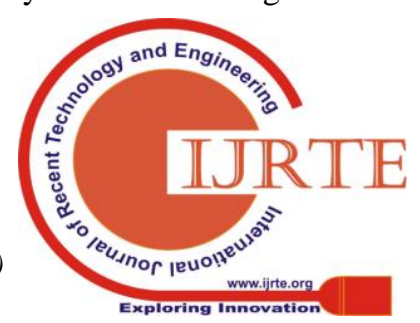



FAME techniques. The subjects in the experiment were made to listen different sentences/words/music with lyrics/music without lyrics in quiet conditions followed by noting it down on a paper if subjects are adults otherwise (in case of child CI users)whatever subjects listened, had to speak and written by parents. Presentation levels of sentences were increased by $2 \mathrm{~dB}$ if subject was not able to understand words. No sentence/words/music was repeated for the same subject. They need to inform which one they feel clearer in case of song with lyrics and in case of song without lyrics.

In case of CI participants, songs are played without any coding and only with different sampling rates. Thus, after hearing the same song with different sampling rates CI participants was asked to speak about in which sampling rate they understood the song more clearly. Here clarity in terms of beats understanding. The songs were played with increased sampling rate up to 48k. Presentation levels of songs were increased by $2 \mathrm{~dB}$ if $\mathrm{CI}$ participants were not able to understand songs.

\section{Experiment1: Best number of channels identification}

In the beginning of CI success, 4 numbers of channels have been used for users. Later on, many experiments have been done on it. Everyone has different aspects with respect to the number of channels which are correct for the user. Thus, in this regard we have also done an experiment which can define minimum number of channels required for the users. This is the reason experiments have been done on different number of channels.

Four methods were conducted with normal hearing persons to evaluate the difference between CIS and FAME. In method 1, 8 channels have been used using 9 set with 10 sentences in each set in a quiet background. In method 2, 3 and 4the same sentences were used but the channel numbers were changed to four, six and sixteen respectively. For the clarity of experiment, all the details have been provided in Table I (print at same place) has been given.

a. Aim: Using different number of channels to identify the correct perception of vowels and consonants with respect to the sentences by the users in quiet at anechoic room.

Table-I: Experimental methods

\begin{tabular}{lllll}
\hline \hline Methods & CIS & FAME & $\begin{array}{l}\text { Sentence } \\
\text { s }\end{array}$ & Background \\
\hline \hline I & $\begin{array}{l}8 \\
\text { Channels }\end{array}$ & $\begin{array}{l}8 \\
\text { Channels }\end{array}$ & 90 & Quiet \\
II & 4 & 4 & 90 & Quiet \\
& Channels & Channels & & \\
III & 6 & 6 & 90 & Quiet \\
& Channels & Channels & & \\
IV & 16 & 16 & 90 & Quiet \\
& Channels & Channels & & \\
\end{tabular}

b. Objective: The study has been done to check the difficulty of different channels with respect to the vowel and consonants identification used in the sentences by normal hearing users.

c. Subject: 20Normal Hearing (NH) participants comprising 10 male and 10 female graduate students ranging from 19 to 25 years of age were participated in
B. Procedure: All the subjects were exposed to CIS and

the experiment. All participants were screened by the questionnaire and were found to have normal hearing behaviour. All participants were graduated or post graduate students. Consent forms were signed by all subjects and volunteered to participate in the study.

d. Apparatus: The stimuli were recorded digitally on a data acquisition system at $44.1 \mathrm{kHz}$ sampling frequency using a 16-bit A/D converter in a sound treated room with Avid Pro Tools, Pro Tools11 model. The recorded speech material was scaled for the same intensity. Computer with digital dual core processor has been used. The output is two channels. SONY headphones of MDR-ZX110A model were used as transducers in case of normal users. In case of CI user, loudspeaker of Sony Mega Bass XS-FB162E 6.5-inch Speakers model has been used instead of headphones.

e. Signal Processing: Speech signals were band pass filtered into 8, 4, 6, 16 frequency bands. The temporal envelopes were extracted from each sub band by full wave rectification and low pass filtering at $500 \mathrm{~Hz}$. The envelope was used to modulate. In spectrally un-shifted condition, the envelope is extracted from $200-7500 \mathrm{~Hz}$ and modulated on a same carrier frequency band i.e. $200-7500 \mathrm{~Hz}$

Design: Total 9 set with 10 different sentences with uniform length and naturalness have been taken in the experiment. In method1, the signals were divided into 8 frequency bands (channel 8). In addition, FIR filters were used with MATLAB. In method 2 the signals were divided into 4 frequency bands (channel 4) with FIR filters and follow the same process as method1. In method 3 and 4, all parameters were retained as in method 2 except that signals were divided into 6 frequency bands (channel 6) in method 3 and signals were divided into 16 frequency bands (channel 16) in method 4.

Under noiseless condition, FAME gave smoother and comfortable hearing as compared to CIS [9, 10, 11, 12, 13, 14]. The results are approximately same in all methods with respect to difference in CIS and FAME. The only change found was that the subjects perceived better voice in channel 6 and channel 8, contrary to channel 4 and 16 . The results of channel 6 and 8 are approximately same.

In this experiment, one user who is using CI for more than a decade of MEDEL Company was also included. The CI user also expressed that 8 channels gave best results when compared to channels 4, 6, 16. MEDEL uses FS4 strategy.

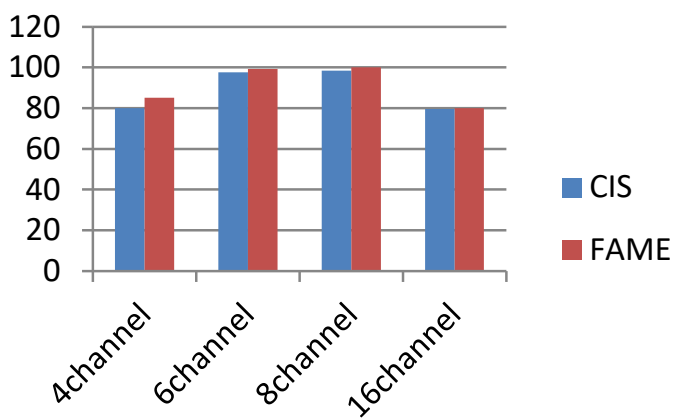

Fig.4 Comparison in percentage with all channels in CIS and FAME

Published By:

Blue Eyes Intelligence Engineering 


\section{Simulated output of Continuous Interleaved Sampling and Frequency Amplitude Modulation Encoding techniques used in Cochlear Implant}

g. Results: From the above study it is clear that all the participants could hear better by using FAME technique as compared to the CIS at 6 and 8 channels. However, at 8 channels performance is best in all cases including the CI user. The important observation is that all participants felt that CIS is harsher in listening when compared to FAME, as there was more uncomfortable for the participants after a certain amount of time during continuous listening via CIS. The difference in these four methods can be seen in Table II and from Fig 4 to $11[15,16,17]$.

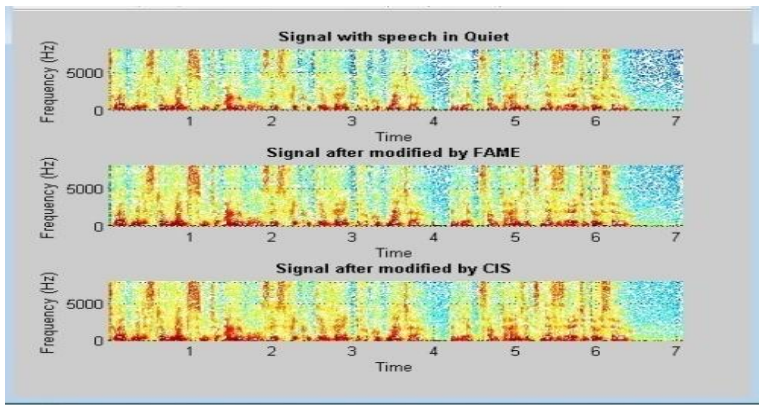

Fig.5 Spectrogram at Quiet

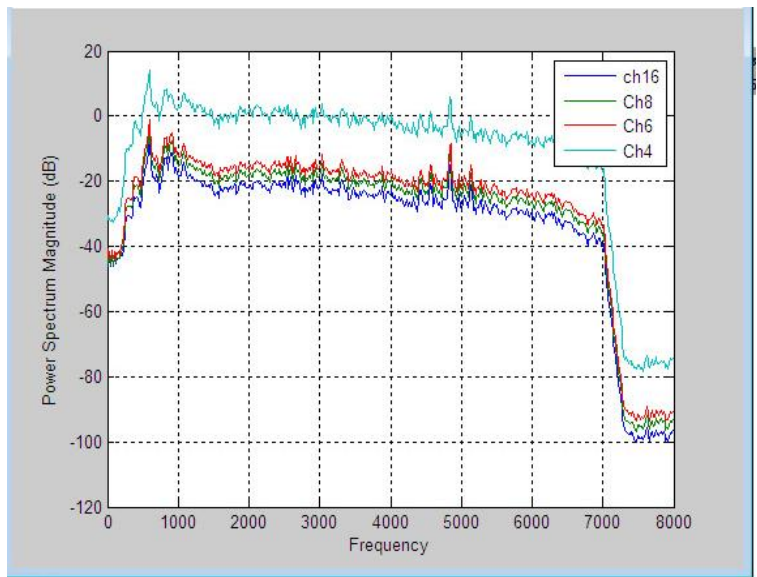

Fig.6 Difference of FAME at Channels 4, 6, 8, 16

It is clear from Figure 5 that in clean speech it is difficult to find the difference in CIS and FAME by spectrogram (Fig 4 to 11 will be print after result of experiment1).

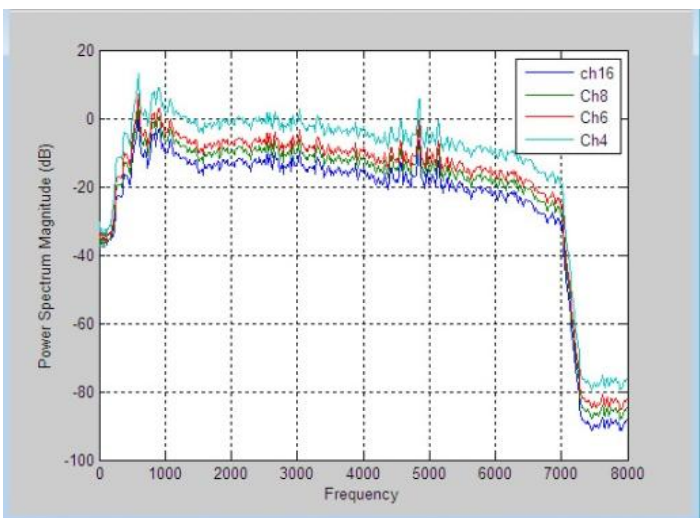

Fig.7 Difference of CIS at Channels 4, 6, 8, 16 
The Fch represents FAME and Cch represents CIS technique in Fig 8,9,10 and 11. techniques behave at different channels individually. In all the four methods, the overall difference in FAME and CIS techniques has been shown (Fig 8). From Fig 8 and Table II it is clear when number of channels is increased the functioning of CIS and FAME are approximately same and feedback from subjects also shows that more than 8 channels degrade the quality of sound. Fig 10 and 11 show that there is a significant difference in the functioning of FAME and CIS and the subjects also expressed better sound quality when 6 or 8 channels are used.

Finally in both the techniques the signals are required to be sent to the electrodes of CI in the form of biphasic pulses. How the signals appear when they are converted to biphasic pulses form can be seen in Fig 12 (Fig 12 should be print here only). This conversion is required because speecld.

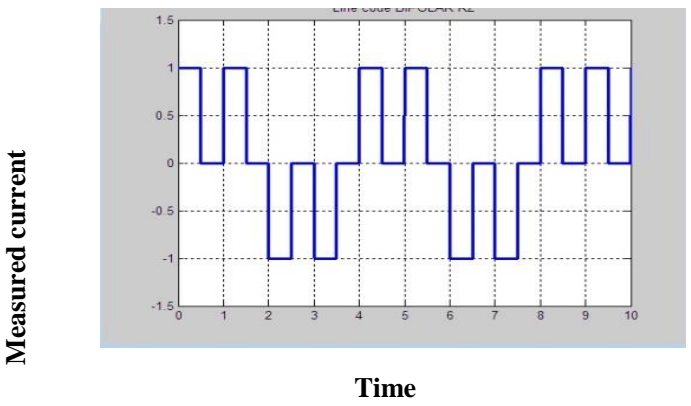

Fig.12 Sound in Biphasic pulses form

\section{Experiment2: Music perception}

Part (a): Normal users are participating for identification purpose which coding technique CIS or FAME is good for music appreciation in respect of CI users.

Part (b): CI users feel problem in understanding music.

Music is having continuous beats while speech is having silence and unvoiced parts in between. Thus CI users can identify speech easily with normal sampling rate. In the case of music, increased sampling rate is required to understand beats which makes sense of the music $[18,19]$.

a. Aim: Using Hindi songs to appreciate the song bf. normal and the CI users in quiet at anechoic room.

b. Objective: The study has been done to check the clarity of different songs by normal subjects and CI users at normal sampling rate with FAME and CIS and at increased sampling rate and without FAME and CIS respectively.

Table-II: Channel \& song information in percentage with respect to clarity by normal users

\begin{tabular}{cccccc}
\hline \hline & & & & & Song clarity \\
Strategy & Channel & $\begin{array}{c}\mathbf{6} \\
\text { channel }\end{array}$ & $\begin{array}{c}\mathbf{8} \\
\text { channel }\end{array}$ & $\begin{array}{c}\mathbf{1 6} \\
\text { channel }\end{array}$ & $\begin{array}{c}\text { by normal } \\
\text { users }\end{array}$ \\
\hline \hline & & & & & \\
CIS & 80 & 97.5 & 98.5 & 79.5 & 90 \\
FAME & 85 & 99.2 & 100 & 80 & 100 \\
\hline \hline
\end{tabular}

user, but minimum requirement is the double sampling rate from the original song sampling rate.(Table II will be print after experiment 2 only).
It can be seen from Fig 6 and 7 that how FAME and CIS signals are sent in the form of bits only.

c. Subject: Total 20 normal hearing by 10 male and 10 female subjects were participated. Screening of the participants has been done with the questionnaire and all were found to have normal hearing. All participants aged between 20 to 30 years. All subjects were graduated and post graduate students. Consent forms were signed by all participants. All participants volunteered to participate in the study.

CI participants also participated in the experiment. Total 5 subjects were present. Participants aged between 10 to 35 year with minimum of 2 year CI experience. All CI participants or their parents (in case they are being minor) had signed the consent form. Factors like the minimum and maximum threshold level of the CI participants had been taken care of such that CI participants did not feel discomfort during experiment. All participants volunteered to participate in the study.

Apparatus: PC with digital dual core processor had been used. The output was with two channels. SONY headphones of MDR-ZX110A model were used as transducers for normal users. In case of CI user's loudspeaker of Sony Mega Bass XS-FB162E 6.5-inch Speakers model is used instead of headphones.

e. Design: Ten types of Hindi songs were played. In which 5 songs are with lyrics and 5 are without lyrics. During the test, songs were chosen randomly (Fig13 will be printing here). The percentage of clarity in both techniques has been shown in Table II and Fig13.

\section{Clarity in percentage}

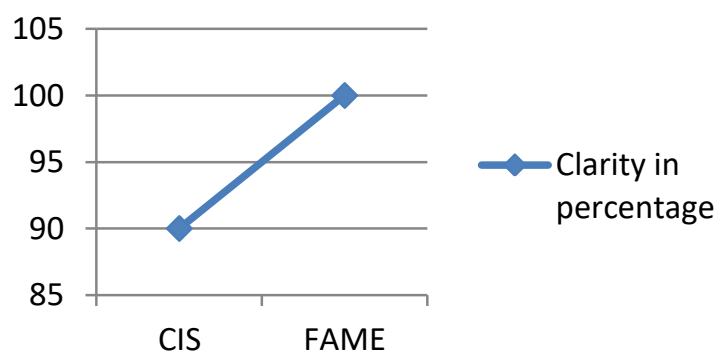

\section{Fig.13 Difference in percentage for Music by CIS and FAME}

Results: From the results it is clear that FAME is giving better performance as compared to CIS. In case of CIS some background noise is present in the songs while in the case of FAME more clarity is present in the songs with or without lyrics.

In the case of CI participants, they felt songs beats more clear when songs sampling rate increased by double or four times by the song real sampling rate. It varied user to

Experiment3: Consonant and vowel perception in words CI users had speech issues when they are pre-lingual, the ones which were born deaf. As in CI through electrodes, only limited frequencies are available for CI users, it is the possibility that some consonants and vowels get mixed because of placements of the electrodes. This is the reason why CI users are not able to understand all consonants and vowels. However, if the pre-lingual implanted at early age than performance is approximately same as post-lingual [20, 21, 22].

a. Aim: Using words to identify the correct perception of vowel and

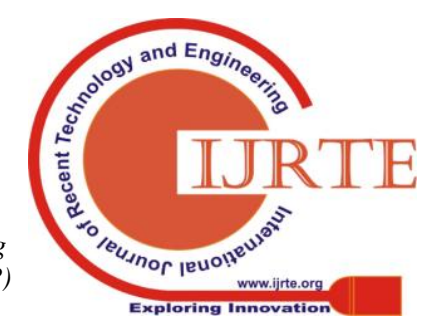




\section{Simulated output of Continuous Interleaved Sampling and Frequency Amplitude Modulation Encoding}

techniques used in Cochlear Implant

consonants by the CI users in quiet at anechoic room.

b. Objective: The study has been done to check the difficulty in identification of different vowel and consonants by CI users without FAME and CIS.

c. Subject: CI subjects participated in the experiment. Total 7 subjects were present. Subjects were aged in the range of 7 to 35 year with minimum of 2 year CI experience. All CI subjects if adults otherwise their parents have signed consent form. All subjects volunteered to participate in the study. All other things such as minimum and maximum threshold level of the CI subject were taken care of so that CI subject did not feel discomfort during experiment.

d. Apparatus: PC with digital dual core processor has been used. The output is two channels. SONY loudspeaker of Sony Mega Bass XS-FB162E 6.5-inch Speakers model is used.

e. Design: Twenty words were played in anechoic room like had, hood, bat, beet, bert, etc. In testing random list of words had been played.

Table-III: Clarity of vowels and consonants in percentage of CI users

\begin{tabular}{lc}
\hline \hline User Type & Clarity in \% \\
\hline \hline CI Implant at late stage & 25 \\
CI Implant at early age & 27.5 \\
\hline \hline
\end{tabular}

f. Results: The results show that CI user felt the difficulty in single word understanding. The percentage of understanding vowel and consonants in single words was between 20 to 30 percentages only. Table III and Fig14 show the difference of understanding by late implanted and early implanted users. Table IV shows the information of CI users and all users electrodes are fully inserted (Table IV should be print near conclusion).

Clarity in percentage

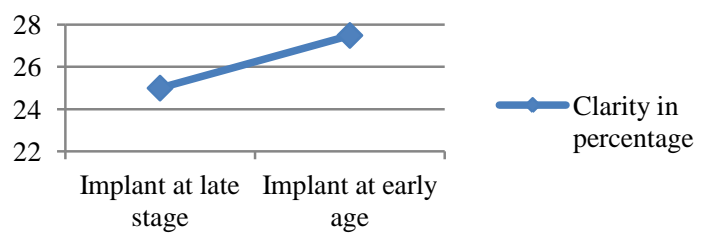

Fig.14 Difference in percentage for vowels and consonant

Table-IV: Cochlear Implant participant's information

\begin{tabular}{|c|c|c|c|c|c|c|c|c|c|}
\hline $\begin{array}{l}\text { S. } \\
\text { N } \\
\text { o. }\end{array}$ & $\begin{array}{l}\text { Co } \\
\text { mpa } \\
\text { ny } \\
\text { Na } \\
\text { me }\end{array}$ & $\begin{array}{l}\text { Etiol } \\
\text { ogy }\end{array}$ & $\begin{array}{l}\text { Yea } \\
\text { r of } \\
\text { hea } \\
\text { ring } \\
\text { loss } \\
\text { star } \\
t\end{array}$ & $\begin{array}{l}\text { Year } \\
\text { of } \\
\text { profo } \\
\text { und } \\
\text { heari } \\
\text { ng } \\
\text { loss }\end{array}$ & $\begin{array}{l}\text { A } \\
\text { ge } \\
\text { at } \\
\mathbf{i} \\
\text { m } \\
\text { pl } \\
\text { a } \\
\text { nt }\end{array}$ & $\begin{array}{l}\mathbf{E} \\
\text { ar }\end{array}$ & Type & $\begin{array}{l}\text { Mo } \\
\text { del } \\
\text { typ } \\
\text { e }\end{array}$ & $\begin{array}{l}\text { Ge } \\
\text { nde } \\
\text { r }\end{array}$ \\
\hline $\begin{array}{l}\mathrm{M} \\
\mathrm{D} \\
1\end{array}$ & $\begin{array}{l}\text { ME } \\
\text { DEL }\end{array}$ & Fever & 14 & 14 & 15 & $\begin{array}{l}\mathrm{Ri} \\
\mathrm{g} \\
\mathrm{ht}\end{array}$ & $\begin{array}{l}\text { Unil } \\
\text { atera } \\
\text { l }\end{array}$ & $\begin{array}{l}\text { Opu } \\
\text { s1 }\end{array}$ & $\begin{array}{l}\mathrm{Fe} \\
\text { mal } \\
\mathrm{e}\end{array}$ \\
\hline $\begin{array}{l}M \\
D \\
2\end{array}$ & $\begin{array}{l}\text { ME } \\
\text { DEL }\end{array}$ & Fever & 20 & 20 & $\begin{array}{l}20 \\
.2\end{array}$ & $\begin{array}{l}\mathrm{Ri} \\
\mathrm{g} \\
\mathrm{ht}\end{array}$ & $\begin{array}{l}\text { Unil } \\
\text { atera } \\
1\end{array}$ & $\begin{array}{l}\text { Opu } \\
\text { s1 }\end{array}$ & $\begin{array}{l}\text { Mal } \\
\mathrm{e}\end{array}$ \\
\hline $\begin{array}{l}\mathrm{C} \\
\mathrm{H} \\
3\end{array}$ & $\begin{array}{l}\text { Coc } \\
\text { hlea } \\
\text { r }\end{array}$ & $\begin{array}{l}\text { Unkn } \\
\text { own }\end{array}$ & 1 & 11.5 & 12 & $\begin{array}{l}\mathrm{Ri} \\
\mathrm{g} \\
\mathrm{ht}\end{array}$ & $\begin{array}{l}\text { Unil } \\
\text { atera } \\
\text { l }\end{array}$ & $\begin{array}{l}\text { CP- } \\
802\end{array}$ & $\begin{array}{l}\mathrm{Fe} \\
\text { mal } \\
\mathrm{e}\end{array}$ \\
\hline C & Coc & Musc & 1.5 & 2.2 & 2. & L & Unil & CP- & $\mathrm{Fe}$ \\
\hline
\end{tabular}

\begin{tabular}{|c|c|c|c|c|c|c|c|c|c|}
\hline $\mathrm{H}$ & hlea & ular & & & 5 & ef & " atera & 800 & $\overline{\mathrm{cmal}}$ \\
\hline 4 & $r$ & $\begin{array}{l}\text { dystr } \\
\text { ophy }\end{array}$ & & & & $\mathrm{t}$ & 1 & & e \\
\hline C & Coc & Here & \multirow[t]{3}{*}{0.5} & \multirow[t]{3}{*}{0.5} & 2. & $\mathrm{Ri}$ & \multirow{3}{*}{$\begin{array}{l}\text { Unil } \\
\text { atera } \\
1\end{array}$} & CP- & \multirow{3}{*}{$\begin{array}{l}\mathrm{Fe} \\
\mathrm{mal} \\
\mathrm{e}\end{array}$} \\
\hline $\mathrm{H}$ & hlea & ditary & & & 5 & g & & 910 & \\
\hline 5 & $r$ & & & & & ht & & & \\
\hline C & Coc & \multirow{6}{*}{$\begin{array}{l}\text { Unkn } \\
\text { own }\end{array}$} & \multirow[t]{6}{*}{1.5} & \multirow[t]{6}{*}{4.5} & \multirow[t]{6}{*}{8} & $\mathrm{Ri}$ & \multirow{6}{*}{$\begin{array}{l}\text { Unil } \\
\text { atera } \\
\mathrm{l}\end{array}$} & Nuc & \multirow{6}{*}{$\begin{array}{l}\mathrm{Fe} \\
\mathrm{mal} \\
\mathrm{e}\end{array}$} \\
\hline $\mathrm{H}$ & hlea & & & & & g & & leus & \\
\hline 6 & $r$ & & & & & ht & & free & \\
\hline & & & & & & & & do & \\
\hline & & & & & & & & $\mathrm{m}$ & \\
\hline & & & & & & & & 24 & \\
\hline C & Coc & \multirow[t]{3}{*}{ Fever } & \multirow[t]{3}{*}{10} & \multirow[t]{3}{*}{14.5} & \multirow[t]{3}{*}{15} & $\mathrm{~L}$ & \multirow{3}{*}{$\begin{array}{l}\text { Unil } \\
\text { atera } \\
1\end{array}$} & CP- & \multirow{3}{*}{$\begin{array}{l}\text { Mal } \\
\text { e }\end{array}$} \\
\hline $\mathrm{H}$ & hlea & & & & & ef & & 810 & \\
\hline 7 & $\mathrm{r}$ & & & & & $\mathrm{t}$ & & & \\
\hline
\end{tabular}

MEDEL uses Fine structure processing (FSP). The difference between FSP and FS4 is FSP incorporate stimulation rate over one or two most apical channel while FS4 provides fine structure processing on up to

four of the most apical channels extending up to $1000 \mathrm{~Hz}$. Currently FS4 has been used in MEDEL.

Cochlear Corporation uses ACE and SPEAK both depends upon user choice at the time of programming.

While in FAME technique all channels are frequency modulated.

\section{CONCLUSION}

All the subjects who participated in the experiments expressed that FAME technique provided better speech recognition, music appreciation and tonal language identification in terms of clarity as compared to the CIS technique. This can also be noted from the Figures presented in the paper.

In case of CI users, vowels and consonants understanding is less in respect of single words. Song understanding is good if sampling rate is increased by double. We used 16 number of channels in our experiment for CIS and FAME both, so that we get the clarity as more number of channels give more clarity to the user or not? In all different coding techniques, we find 8 numbers of channels when used simultaneously give best results to the users in terms of clarity in both CIS and FAME strategy.

Hence, it is concluded that FAME technique is better than CIS technique in performance. Based on this result we will propose an intelligent preprocessor whose output will be the input to the FAME based CI system to enhance the speech quality for CI Users.

\section{ACKNOWLEDGEMENT}

We are thankful to the participants for their active participation in our experiment. We are also thankful to DEBEL-DRDO and SBMT (Society for Biomedical Technology), Bangalore for giving us necessary help and support in the form of guidance, infrastructure and facilities for carrying out my work in this area.

\section{REFERENCES}

1. Fan-Gang Zeng*†t, KaibaoNie*, Ginger S. Stickney*, Ying-Yee Kong*, Michael Vongphoe*, Ashish Bhargave*, Chaogang Wei $\uparrow$, and Keli Cao†, Speech recognition with amplitude and frequency modulations, PNAS February 15, 2005 vol. 102 no. 7 2293-2298.

Published By:

Blue Eyes Intelligence Engineering and Sciences Publication (BEIESP) (C) Copyright: All rights reserved.

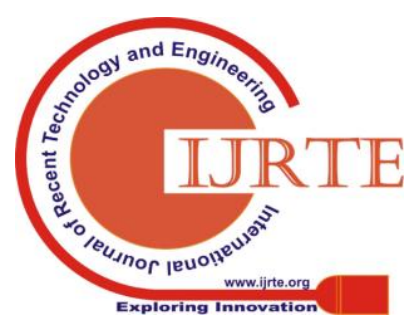


2. Kaibao Nie, Ginger Stickney, and Fan-Gang Zeng*, Encoding Frequency Modulation to Improve Cochlear Implant Performance in Noise, IEEE transactions on biomedical engineering, VOL. 52, NO. 1, January 2005

3. Blake S. Wilson, PhD ; Charles C. Finley, PhD; Dewey T. Lawson, PhD; Robert D. Wolford, MS; Mariangeli Zerbi, MSEE Design and evaluation of a continuous interleaved sampling (CIS) processing strategy for multichannel cochlear implants, Journal of Rehabilitation Research and Development Vol . 30 No. 1, 1993 Pages 110-116

4. Cong-Thanh Do, Acoustic Simulations of Cochlear Implants in Human and Machine Hearing Research, http://www.intechopen.com/books/cochlear-implant researchupdates.

5. Signals and System by Alan V. Oppenheim, Paperback 2015, Second Edition.

6. Programming Cochlear implants, by Jace Wolfe, Erin c. schafer, Second Edition.

7. Serge M Petrov, Medical Group, Modeling of Cochlear Implants with Different Frequency Ranges by Means of Spectrally Deprived Speech, Journal of Otolaryngology-ENT Research, Volume 6 Issue 4 $-2017$.

8. Kevin H. Franck, Anupam Mishra, Pediatric Cochlear Implantation - I : Candidacy, Indian Journal of Otolaryngology and Head and Neck Surgery Vol 55 No 2 April June 2003.

9. Fan-Gang Zeng, Stephen Rebscher, William V. Harrison, Xiaoan Sun, Haihong Feng, Cochlear Implants: System Design, Integration and Evaluation, IEEE Rev Biomed Eng. 2008 January 1; 1: 115-142. doi:10.1109/RBME.2008.2008250.

10. XinLuo and Qian-Jie Fu, Frequency modulation detection with simultaneous amplitude modulation by cochlear implant users, Article in The Journal of the Acoustical Society of America - September 2007 DOI: 10.1121/1.2751258 · Source: PubMed

11. 11.Varun G Rai, AttigoduChandrashekara Ganesh, Environmental Sound Perception with Amplitude and Frequency Modulations in Simulated Cochlear Implant, The Journal of International Advanced Otology

12. Richard E. Turner, Maneesh Sahani, Probabilistic amplitude and frequency demodulation, Turner and Sahani Probabilistic amplitude and frequency demodulation, NIPS 2011 Pre-conference version

13. Ginger S. Stickney, Peter F. Assmann, Janice Chang, Fan-Gang Zeng, Effects of cochlear implant processing and fundamental frequency on the intelligibility of competing sentences, (C) 2007 Acoustical Society of America. DOI: 10.1121/1.2750159PACS numbers: 43.66.Ts, 43.71.Ky, 43.71.Bp, 43.66.Hg_KWG_Pages: 1069-1078

14. 14.Y.Srinivas,P.Darwin,V.Sailja, Continuous Interleaved Sampled (CIS) Signal Processing Strategy for Cochlear Implants MATLAB Simulation Program, International Journal of Scientific \& Engineering Research Volume 3, Issue 12, December-2012 1 ISSN 2229-5518.

15. 15. Deepti Gupta, Pratistha Mathur, Peeyush Tewari, Existing Noise Removal Techniques Used In Cochlear Implant, International Journal of Advanced research in Science and engineering, vol. No.5, Issue No. 3,March 2016.

16. 16. Deepti Gupta, Pratistha Mathur, Peeyush Tewari, Signal processing and neural network techniques used in Cochlear Implant for different types of noises, International Research Journal of Engineering and Technology (IRJET) e-ISSN: 2395 -0056 Volume: 03 Issue: 06 | June-2016 , www.irjet.net p-ISSN: 2395-0072

17. 17. Audio wave files for different environmental sounds retrieved from http://www. findsounds.com/.

18. 18. Meinard Müller, Daniel P. W. Ellis, AnssiKlapuri, and Gaël Richard, Signal Processing for Music Analysis, IEEE journal of selected topics in signal processing, vol. 0, no. 0, 2011

19. 19. Hugh J. McDermott, Music Perception with Cochlear Implants: A Review, Trends In Amplification Volume 8, Number 2, 2004.

20. 20. P. J. Blamey, P.C. Dowell, A. M. Brown and C. M. Clark, volume 82, issue1 :https://doi:org/10.1121/1.395436.

21. 21. Paul Iverson, Charlotte A. Smith, Bronwen G. Evans, Vowel recognition via cochlear implants and noise vocoders: Effects of formant movement and duration, 2006 Acoustical Society of America. DOI: 10.1121/1.2372453, Pages: 3998-4006

22. 22. MishaelaDiNino, Richard A.Wright, Matthew B.Winn, and Julie Arenberg Bierer, Vowel and consonant confusions from spectrally manipulated stimuli designed to simulate poor cochlear implant electrode-neuron interfaces, 2016 Acoustical Society of America. http://dx.doi.org/10.1121/1.4971420, pages:4404-4418.

\section{AUTHORS PROFILE}

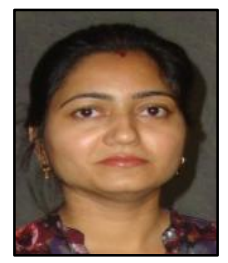

Deepti Gupta is currently pursuing $\mathrm{PhD}$. She worked 7years in a college affiliated to Indraprastha University as an assistant professor. Her area of Interest is signal processing techniques related to Cochlear Implant.

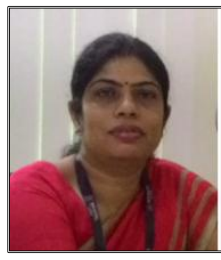

Pratistha Mathur is currently working in Dept. of Information Technology, Manipal University Jaipur Since July 2016. She served over 18 years at Banasthali Vidyapith, Rajasthan. Her area of interest includes Image Processing, Soft computing, Artificial Intelligence and Indian Language Computing. She is the author of more than 40 research articles and 2 books. She can be reached at mathurprati@yahoo.com.

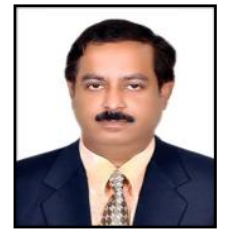

Peeyush Tewari, did MSc, Ph.D (Applied Mathematics), from IIT Roorkee, India. Working a BIT Mersa Ranchi, India since 1991. Worked at BIT International centre in Sultanate of Oman and united Arab Emirates. Research Area includes Moving Boundary Problems: applications in geophysical Modelling, Level set methods in Image processing and Supply Chain Management. Book Chapter in Nano-technology 2009: Fabrication, Particles, Characterization, MEMS, Electronics and Photonics, Editorial board member of International Journal of Intelligent Information Processing.

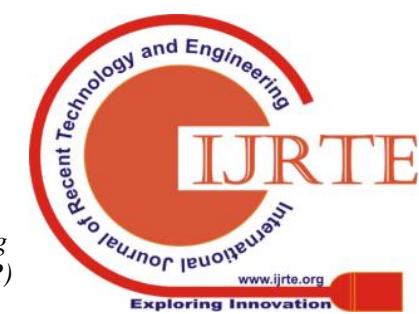

